Elsevier required licence: @ 2018. This manuscript version is made available under the CC-BY-NC-ND 4.0 license http://creativecommons.org/licenses/by-nc-nd/4.0/

The definitive publisher version is available online at https://doi.org/10.1016/j.jcsr.2018.09.001 


\section{EXPERIMENTAL STRESS CONCENTRATION FACTOR IN CONCRETE-FILLED STEEL TUBULAR T-JOINTS}

Idris A. Musa ${ }^{a^{*}}$, Fidelis R. Mashiri ${ }^{\mathrm{a}}$, Xinqun Zhu ${ }^{\mathrm{b}}$, Lewei Tong ${ }^{\mathrm{c}}$

${ }^{a}$ School of Computing, Engineering and Mathematics, Western Sydney University, Sydney, NSW 2751, Australia.

${ }^{\mathrm{b}}$ School of Civil and Environmental Engineering, University of Technology Sydney, Sydney, NSW 2007, Australia.

${ }^{c}$ State Key Laboratory for Disaster Reduction in Civil Engineering, Tongji University, Shanghai 200092, China

\section{ABSTRACT}

Experimental investigation of stress concentration factor (SCF) in Steel circular hollow section brace welded to concrete-filled circular hollow section chord (CHS-to-CFCHS) T-joints has been performed under axial tension, axial compression, in-plane bending and out-of-plane bending. The distribution of SCF around the welded brace-to-chord intersection on both the brace and chord has been investigated using three CHS-to-CFCHS T-joint specimens. The experimental SCF results have been compared with the predicted SCF in empty T-joints. The relationship between the maximum $\mathrm{SCF}$ in relation to parameter $\beta$, with fixed other geometrical parameters, has been investigated for the basic load conditions. The experimental maximum SCF under axial tension has been compared with the predicted maximum SCF from parametric equations for CHS-to-CFCHS T-joints previously developed by the authors. The results show that the concrete has a significant effect in reducing the SCF, mostly under axial tension and the parametric equations for predicting SCFs in empty T-joints are not suitable for CHS-to-CFCHS T-joints. The effect of parameter $\beta$ on the maximum SCF in CHS-to-CFCHS T-joints is significant under axial tension and out-of-plane bending moment.

Keywords: Concrete-filled steel tubular T-joints, Stress concentration factor, Fatigue

\footnotetext{
* Corresponding author: I.Musa@westernsydney.edu.au
} 


\section{INTRODUCTION}

Steel tubular structural members are being increasingly used in engineering structures. One of the advantages of the steel tubular members is the high stiffness to cross sectional area ratio in all directions when compared to non-tubular structural members. Despite increasing the self-weight, concrete filling the steel tubular members is one of the cheapest and most effective ways in enhancing the overall performance of the member. In the last two decades, many concrete-filled steel tubular arch bridges have been built in China (Chen and Wang [1]). The bridge arches are usually made of uniplanar and multi-planar CHS-to-CFCHS T- and K-joints. The tubular joints are subjected to repetitive loading from traffic which cause fatigue problems.

Fatigue strength is one of the key factors that control the design of steel tubular joints. Due to geometric discontinuity at the welded steel tubular joints, high stress concentrations exist at the vicinity of the weld. Fatigue cracks usually initiate at the location of the highest stress concentration. Concrete filling of the steel tubes can effectively reduce stress concentrations at the joint and hence eliminate or delay fatigue crack initiation. The hot spot stress method is one of the widely used fatigue design methods and uses the geometrical stress concentrations at the vicinity of the weld in the fatigue design. It uses the geometric stress where the effect of geometry but not that of the local notch is considered in the design. The maximum geometric stress is the hot spot stress. The maximum stress concentration factor $\left(\mathrm{SCF}_{\max }\right)$ is the ratio of the maximum geometric stress to the governing nominal stress which is causing the geometric stress. $\mathrm{SCF}_{\max }$ is used in the hot-spot stress method along with an appropriate S-N curve to estimate fatigue life of tubular joints. Stress concentration in welded T-joints made of a steel circular hollow section (CHS) brace welded to a concrete-filled circular hollow section (CFCHS) chord have been investigated experimentally by several researchers. Jardine [2], investigated SCF's in previously fatigue damaged then repaired CHS-to-CFCHS T-joints under axial force, in-plane bending and out-of-plane bending. Tong et al. $[3,4]$, performed an experimental study on the distribution of the SCF around the brace-chord intersection in CHS-to-CFCHS T-joints subjected to axial loading and in-plane bending moment. Chen et al. [5], conducted experiments on CHS-to-CFCHS T-joints subjected to axial loading and inplane bending to investigate the distribution of SCF's in the joints. Wang et al. [6], investigated the 
distribution of SCF's in CHS-to-CFCHS T-joints for fatigue purposes. Xu et al. [7], experimentally investigated SCF's in thin-walled CHS-to-CFCHS T-joints subjected to axial tension. Generally, from the above-mentioned studies, it was concluded that it would be conservative to use SCF design predictions for empty joints in predicting SCF's in CHS-to-CFCHS joints. It was found that concrete-filling the chord effectively reduced SCF's in CHS-to-CFCHS joints. Apart from the Jardine [2] study, which was on repaired CHS-to-CFCHS T-joints, no investigation on SCF's in CHS-to-CFCHS T-joints under out-of-plane has been reported in the literature. The T-joints in arch bridges will definitely undergo out-of-plane moments and hence require thorough investigation.

In this paper, three circular hollow section concrete-filled steel tubular (CHS-to-CFCHS) T-joints have been subjected to static test under axial tension, axial compression, in-plane bending and outof-plane bending. The effect of concrete filling the chord on the SCF's was assessed. The SCF results were compared against SCFs in empty $\mathrm{T}$-joints calculated from parametric equations for empty T-joints reported in CIDECT (International Committee for the Development and Study of Tubular Construction) [8], DNV.GL (Det Norske Veritas) [9], and Lloyd's Register design guide $[10,11]$. The results compliment current research in this area. The results have shown that concrete infill effectively reduces SCF's under all loading formats and the parametric equations for predicting SCFs in empty T-joints under all loading formats are not suitable for CHS-to-CFCHS T-joints.

Table 1. Notations

$D=$ Chord external diameter

$d=$ Brace external diameter

$T=$ Chord thickness

$L=$ Length of chord

$t=$ Brace thickness

$2 \gamma=$ Chord wall slenderness ratio $=\mathrm{D} / \mathrm{T}$

$\beta=$ Brace-to-chord diameter ratio $=\frac{d}{D}$

$\alpha=$ Chord length-to-half chord diameter ratio $=\frac{2 L}{D}$

$\tau=$ Brace-to-chord thickness ratio $=\frac{t}{T}$

$E_{s}=$ Modulus of elasticity of the steel

$E_{c}=$ Modulus of elasticity of the concrete

$f_{y}=$ Yield strength of the steel $f_{u}=$ Ultimate strength of the steel

$\varepsilon_{f}=$ Elongation in the steel at fracture

$\varepsilon_{h s}=$ Hot spot strain

$\varepsilon_{n}=$ Normal strain

$\mathrm{Cc}=$ Chord crown

$\mathrm{Cs}=$ Chord saddle

$\mathrm{Bc}=$ Brace crown

$\mathrm{Bs}=$ Brace saddle

$\mathrm{SCF}=$ Stress concentration factor

$\mathrm{SCF}_{\max }=$ Maximum stress concentration factor CHS $=$ Circular hollow section

CHS-to-CFCHS $=$ Steel circular hollow section (CHS) brace welded to concrete-filled circular hollow section (CFCHS) chord 
CIDECT $=$ International Committee for the Development and Study of Tubular Construction API $=$ American Petroleum Institute
$\mathrm{DNV}=$ Det Norske Veritas

LR design guide $=$ Lloyd's Register design guide

\section{Experimental study}

\subsection{Test Specimens}

Tong et al. [3] and Musa et al. [12] found that parameter $\beta$ is the most influential parameter on SCF in CHS-to-CFCHS T-joints under axial loading. Hence, in order to determine the effect of parameter $\beta$, on the SCF's, the dimensions of the three CHS-to-CFCHS T-joint specimens were chosen so that only parameter $\beta$ varies between $0.29-0.69$ while all the other parameters, $(\tau, \gamma, \alpha)$ were kept constant; for explanation symbols see Table 1. The non-dimensional geometrical parameters and dimensions of the specimens are given in Table 2. The test specimens were fabricated from cold formed circular hollow steel tubes of grade C250LO. Tensile coupons were taken from both the brace and chord and subjected to tensile tests according to AS1391 [13]. The mechanical properties of the chord and brace for the three specimens are given in Table 3 . The brace was butt welded to the chord according to the American Welding Society specifications [14]. The chord was filled with concrete along its full length. The average compressive strength of the concrete test cylinders at 28 days of age was $36 \mathrm{MPa}$. Two $20 \mathrm{~mm}$ thick steel plates were welded to both ends of the chord to facilitate connection of the two end brackets. Additionally, a $20 \mathrm{~mm}$ steel plate was welded to the top end of the brace to facilitate load application.

\subsection{Test loading and boundary conditions}

The chord ends were bolted to two end brackets which were pin connected as shown in

Figure 1. A universal test rig with three hydraulic jacks was employed to test the specimens in three modes of loading, one for axial tension and axial compression, the second one for inplane bending and the third one for out-of-plane bending (see Figures 2-4). For axial loading, 
a vertical load through the brace centreline was applied at the top end of the brace. A horizontal force parallel to the chord centreline was applied to the top end of the brace for the in-plane bending case. For out-of-plane bending, a horizontal load perpendicular to the chord centreline was applied to the top end of the brace. It is worth to mention that the three loading modes were applied individually. During the loading process, the specimen was loaded several times in a shakedown process to release any residual stresses and to break the bond between the chord wall and the concrete as recommended by DNV.GL manual [9] (though it is expected to self-break due to shrinkage of concrete). This is because the bond between the chord wall and the concrete is expected to deteriorate after a few cycles of loading. Then, a cycle of five quasi-static loads was applied. The applied loads were $5 \%, 10 \%, 15 \%, 20 \%$ and $30 \%$ of the maximum static capacity of the joint which was calculated according to the design formulae for empty CHS T-joints given in CIDECT [15]. This level of loading generally falls within the elastic response range of the connection under brace loading.

\subsection{Measurement locations}

Five element strip strain gauges were attached around the brace-chord intersection at $45^{\circ}$ intervals as shown in Figure 5. To measure the actual applied load on the brace, four single element strain gauges were attached on the outer surface half way between the two brace ends at $90^{\circ}$ intervals at a distance more than $2.5 \mathrm{~d}$ from the weld toe as recommended by CIDECT [8]. Additionally, two single element strain gauges were attached on the brace half way between the brace top end and the four single element gauges at the mid-brace so that one of them was at the in-plane position and the other was at the out-of-plane position. This is to have sufficient strain readings to be used for obtaining the nominal strains at the weld toe in the in-plane and out-of-plane bending modes. The arrangement of the strip strain gauges around the weld at the brace-chord intersection followed the linear extrapolation region recommended by CIDECT [8] (Listed in Table 4). 


\subsection{Determination of stress concentration factor}

The strains at the weld toe around the intersection to be considered in the calculations need to be the geometric strain without the effect of the local weld toe geometry. Hence, strain measurements outside the region influenced by weld toe notch need to be extrapolated to the weld toe. The extrapolation region recommended by CIDECT [8] has been adopted in this study. Two extrapolation methods can be used in the determination of hot spot strains, the linear or quadratic extrapolation of the strain measurements. According to CIDECT [8], the linear extrapolation can be used in empty circular hollow section (CHS) joints because strain gradient around the weld toe is generally linear. From the test results obtained in the current study, it was observed that the strain gradient around the intersection was linear on the chord, but it was relatively non-linear on the brace. The non-linearity in the strain gradient on the brace was insignificant since the difference between SCFs obtained using the quadratic and linear methods was very small. Hence, the linear extrapolation method over an extrapolation region recommended by CIDECT [8] for CHS joints, was used to obtain hot spot strains at the weld toe. The strain concentration factor (SNCF) was obtained as the ratio of the hot spot strain at the weld toe to the maximum normal strain in the brace. This relationship is given in Equation(1).

$$
S N C F=\frac{\varepsilon_{h s}}{\varepsilon_{n}}
$$

The SNCF was then converted to a stress concentration factor (SCF) using the relationship recommended by CIDECT [8], which is:

$$
S C F=1.2 \times S N C F
$$




\section{EXPERIMENTAL RESULTS AND DISCUSSION}

\subsection{Axial tension and compression}

The distribution of the SCF around the weld toe, under axial tension and compression, on the chord and brace side is presented in Figures 6-15 and tabulated in Table 5. Figures 6, 8, 10 and 12 show that the SCF distribution on the chord-side under axial tension changes from slightly non-uniform, in T-1, to nearly uniform in T-2 and then to highly non-uniform in T-3. This observation is related to the combination of stresses caused by the local brace load effect and by the chord stresses due to chord bending. For the chord crown the chord stresses become more important for higher chord bending caused by higher brace loads, thus for higher $\beta$ ratios. The authors have also carried out an extensive finite elements analysis to determine the influence of various parameters in CHS-to-CFCHS T-joints as reported in Musa et al. $[12,16])$. It can also be observed in Figure 14 that the SCF distribution on the brace-side under axial tension changes from non-uniform in $\mathrm{T}-1$ to uniform in $\mathrm{T}-3$ which is opposite to that in the chord. Figures 7, 9, 11, 13 and 15 show that the SCF distribution on the chord-side under axial compression is similar in all the three specimens while it changes from almost perfectly uniform in $\mathrm{T}-1$ to non-uniform in $\mathrm{T}-3$ on the brace-side. The SCF results in Table 5 show that the SCF is always greater under axial tension than under axial compression except for the brace crown position. It can also be observed that the SCF on the chord-side is always greater than that on the brace-side under both axial tension and compression. Most of the fatigue design guidelines provide parametric equations for predicting SCFs in empty Tjoints under various loading patterns. DNV.GL manual [9], ISO-19902:2007 [17] and the latest edition of the American Petroleum Institute's recommended practice [18] which all use a relation to the Efthymiou equations [19], provide parametric equations for predicting SCFs in CHS-to-CFCHS T-joints. DNV.GL [9], ISO-19902:2007 [17] and API [18] provide the same expressions for SCF calculation in simple tubular joints. In the DNV.GL manual [9], ISO-19902:2007 and API [18], parametric equations for predicting SCFs in empty joints can 
be used to predict SCF in CHS-to-CFCHS joints after modifying the chord wall thickness in the $\gamma$ term for the saddle SCF calculation for brace and chord to an equivalent chord wall thickness. The limitation here is that the prediction of the SCF at crown positions in both empty and CHS-to-CFCHS T-joints will be the same. However, the comparison in Tables 6 and 8, shows that the SCF at the crown position in CHS-to-CFCHS T-joints is lower than that in empty T-joints. The SCFs at saddle locations in T-joints under in-plane bending moment are negligible.

Tables 6 and 7 show comparison of the experimental SCF results for CHS-to-CFCHS Tjoints under axial tension obtained in the current study with those for empty T-joints under axial tension predicted in CIDECT [8], DNV.GL [9] and LR design guide [10, 11]. It can be observed that the design prediction for SCF's in empty T-joints is not suitable for CHS-toCFCHS T-joints as the prediction is mostly conservative. Table 8 shows a comparison between the SCF in CHS-to-CFCHS T-joints from test results and those predicted by DNV.GL [9] for CHS-to-CFCHS T-joints under axial tension. The results in Table 8 are comparable for the chord crown positions and for the chord saddle for specimen T-1 only. The distribution of the SCF's on the chord and brace in specimen CS-203-133AX which is a CHS-to-CFCHS T-joint specimen tested by Chen et al. [5] under axial tension, with parameters $\beta=0.66, \gamma=12, \tau=0.8$, is quite similar to that in specimen T-3 under axial tension. Specimen CS-203-133AX has different values of parameters $\tau$ and $\gamma$ compared to specimen T-3, but the SCF distribution in the two CHS-to-CFCHS T-joints is similar. This is because parameter $\beta=0.66$ in specimen $C S-203-133 \mathrm{AX}$ is close to that in specimen $\mathrm{T}-3(\beta=0.69)$. This again indicates that parameter $\beta$ is the dominant one. No detailed SCF distribution is given in Tong et al. [3] and Wang et al.[6], therefore a comparison could not be made. 


\subsubsection{The Maximum SCF under axial loading}

The maximum SCF $\left(\mathrm{SCF}_{\max }\right)$ under axial tension is located at the chord saddle location in specimens T-1 and T-2 while it is located at the chord crown in specimen T-3, see Table 5. This observation is related to the combination of stresses caused by the local brace load effect and by the chord stresses due to chord bending as described earlier. For the chord crown the chord stresses become more important for higher chord bending caused by higher brace loads, thus for higher $\beta$ ratios. The authors have also carried out an extensive finite elements analysis to determine the influence of various parameters in CHS-to-CFCHS T-joints as reported in Musa et al. [12,16] . This is also verified by Wang et al. [6]. The locations of the $\mathrm{SCF}_{\max }$ in all specimens tested by Wang et al. [6], which have $\beta \geq 0.54$, are at the crown position. Under axial compression, the location of the maximum SCF is located at the chord crown for all three specimens, see Table 5. Figure 16 shows that the trend in variation of the maximum SCF ( $\left.\mathrm{SCF}_{\max }\right)$ in CHS-to-CFCHS T-joints from test results with parameter $\beta$ under axial tension and compression is similar. Table 9 shows a comparison between the maximum SCF in CHS-to-CFCHS T-joints obtained in this study and those predicted by parametric equation for CHS-to-CFCHS T-joints developed by Musa et al. [12]. There is a good comparison between the current test results and those predicted by the parametric equation. Figure 17 shows the trend in variation of the maximum SCF under axial tension with parameter $\beta$ predicted by CIDECT [8], DNV.GL [9], and LR design guides [10, 11] for empty T-joints and predicted by DNV.GL [9], Musa et al. [12] and the current study for CHS-to-CFCHS T-joints. Figure 17 shows that the maximum SCF in CHS-to-CFCHS Tjoints is much lower than that in empty T-joints. Also, it can be observed that the parametric equation by Musa et al. [12] can reasonably predict the trend in variation and give comparable maximum SCF results. In Wang et al. [6], three CHS-to-CFCHS T-joints have similar parameters $\tau$ and $\gamma$ as in the current study. More specifically, in Wang et al. [6], for specimens CFCHS-1, CFCHS-2 and CFCHS-3 parameters $\tau$ and $\gamma$ are fixed while parameter 
$\beta$ varies from 0.54 to 1 . The variation of the maximum SCF under axial loading, measured in the current study and by Wang et al. [6], with parameter $\beta$ is shown in Figure 18. It can be easily observed in Figure 18 that the trend in variation of the $\mathrm{SCF}_{\max }$ with parameter $\beta$ in the current study is complementary to that in Wang et al. [6]. A similar trend has been predicted by Musa et al. [12] in their extensive finite element modelling of CHS-to-CFCHS T-joints. It is worth to mention that the concrete compressive strength $f_{c}^{\prime}$ in the current study is different from that in Wang et al. [6], but the trend in variation of the $\mathrm{SCF}_{\max }$, shown in Figure 18, is consistent because the concrete grade has very little effect (negligible) on the SCF.

\subsection{In-plane bending}

The distribution of the SCF around the weld toe, under in-plane bending, on the chord and brace side is presented in Figures $19-23$. It can be observed in Figures $19-21$ that the SCF on the tension side is always greater on the chord than that on the brace, while on the compression side at the crown position the SCF is higher on the brace than on the chord. This is because parameter $\tau \approx 1$ for all the specimens tested in the current study. It is worth to mention that the authors (Musa et al. [20]), in an extensive finite element simulation study, found that for $0.2 \leq \tau \leq 0.4$ the SCF on the tension side is always greater on the brace than that on the chord. Figures $22-23$ show that the distribution of the SCF on the chord and the brace is rather similar in the three specimens which indicates that parameter $\beta$ has no remarkable effect on the SCF under in-plane bending. Tong et al. [4] tested the same specimens reported by Wang et al. [6] under in-plane bending. In Tong et al. [4], specimens CFCHS-1, CFCHS-2 and CFCHS-3 have similar values of parameters $\tau$ and $\gamma$ as in the current study while the parameter $\beta$ varies from 0.54 to 1 . Figures $24-25$ show the variation of the SCF on the tension side, measured in the current study and by Tong et al. [4] for CHSto-CFCHS T-joints and those predicted by CIDECT [8], DNV.GL [9] and the LR design guide $[10,11]$ for empty $\mathrm{T}$-joints, with parameter $\beta$. Figures $24-25$ show that the variation 
of the SCF on the chord crown - tension side in CHS-to-CFCHS T-joints is similar to that in empty T-joints while it is opposite on the brace crown - tension side. It can also be observed in Figures $24-25$ that parameter $\beta$ has a considerable effect on the SCF's in both CHS-toCFCHS and empty T-joints under in-plane bending (The difference in SCF when $\beta=0.2$ and $\beta$ $=1$ is close to a factor 2). In the three CHS-to-CFCHS T-joint specimens tested by Chen et al. [5] under in-plane bending the SCF distribution on the chord side (shown in Figure 26) is similar to that in the three specimens under in-plane bending tested in the current study and shown in Figure 22. On the brace side, the SCF distribution observed by Chen et al. [5] (shown in Figure 27) on the compression side is similar to that in the current study and shown in Figure 23, but it is slightly different on the side under tension. Tables 10 and 11 show the comparison of the experimental SCF results for CHS-to-CFCHS T-joints under in-plane bending obtained in the current study with those for empty T-joints under in-plane bending predicted in CIDECT [8], DNV.GL [9] and LR design guide [10, 11]. It can be observed that the design prediction for SCF in empty T-joints is not suitable for CHS-to-CFCHS T-joints as the prediction is conservative. Hence, there is need for further research to develop parametric equations for predicting SCFs in CHS-to-CFCHS T-joints under in-plane bending.

\subsubsection{The maximum SCF under in-plane bending}

Figure 28 shows the variation of the maximum SCF, measured in the current study and by Tong et al. [4], for CHS-to-CFCHS T-joints and those predicted by CIDECT [8], DNV.GL [9] and the LR design guides [10, 11] for empty T-joints under in-plane bending, versus parameter $\beta$. In Figure 28, one of the data points by Tong et al. [4] is anomalous because it is well below the other data points. No explanation could be made due to unavailability of details of the tests. It can be observed in Figure 28 that parameter $\beta$ has little effect on the maximum SCF in both CHS-to-CFCHS and empty T-joints under in-plane bending. In Figures 19-23, it can be observed that the location of the maximum SCF varies from chord 
crown - tension side to brace crown - compression side. Moreover, the variation of the maximum SCF with parameter $\beta$ is opposite in CHS-to-CFCHS compared with empty Tjoints. Generally, under in-plane bending, the concrete infill has a greater impact in reducing the maximum SCF when $\beta<1$.

\subsection{Out-of-plane bending}

The distribution of the SCF around the weld toe, under out-of-plane bending, on the chord and brace side is shown in Figure 29. As discussed in Musa et al. [21], it can be observed in Figure 29 that the SCF on the tension side is always greater on the chord than that on the brace, while on the compression side, the SCF on the brace is greater. Figure 29 also shows that the SCF on the chord side under tension is greater than that on the compression side for the three specimens. Table 12 show comparison of the experimental SCF results for CHS-toCFCHS T-joints under out-of-plane bending obtained in the current study with those for empty T-joints under out-of-plane bending predicted in CIDECT [8], DNV.GL [9] and LR design guides $[10,11]$. It can be observed that the design prediction for SCF in empty Tjoints is not suitable for CHS-to-CFCHS T-joints as the prediction is conservative. Hence, further research is required to develop parametric equations for predicting SCFs in CHS-toCFCHS T-joints under out-of-plane bending.

\subsubsection{The maximum SCF under out-of-plane bending}

It can be easily observed in Figure 29 that the maximum SCF under out-of-plane bending always exists at the chord saddle - tension side. Figure 30 shows the variation of the maximum SCF under out-of-plane, in CHS-to-CFCHS T-joints from test results and predicted by CIDECT [8], DNV.GL [9] and LR design guides [10, 11] for empty T-joints, with parameter $\beta$. It can be observed in Figure 30 that concrete infill has effectively reduced the SCF. It can also be observed that the trend in variation of the maximum SCF with 
parameter $\beta$ is similar in both CHS-to-CFCHS and empty T-joints although it is steeper in empty T-joints.

\section{CONCLUSIONS}

Three CHS-to-CFCHS T-joints have been tested experimentally under axial tension, axial compression, in-plane bending and out-of-plane bending in the brace. SCF measurements in the three specimens under the three loading formats have been performed and compared with those for empty T-joints. The following conclusions can be made:

- Concrete infill effectively reduces the SCF under all loading cases.

- Parametric equations for predicting SCFs in empty T-joints are not suitable for CHSto-CFCHS T-joints.

- $\mathrm{SCF}$ in CHS-to-CFCHS T-joints under axial tension is always greater than that under axial compression except at the brace crown position.

- In CHS-to-CFCHS T-joints under axial compression, the maximum SCF is always located at chord crown position. Under axial tension, the maximum SCF is usually located at the chord saddle position for $\beta<0.5$ and it is located at the chord crown position when $\beta>0.5$.

- The trend in variation of the $\mathrm{SCF}_{\max }$ in CHS-to-CFCHS T-joints with parameter $\beta$ under axial tension and compression is similar (see Figure 16).

- Trend in variation of the maximum SCF with parameter $\beta$ in CHS-to-CFCHS T-joints under axial tension and in-plane bending is opposite to that in empty T-joints (see Figure 17 and 28) while it is similar under out-of-plane bending (see Figure 30).

- Effect of parameter $\beta$ on the maximum SCF in CHS-to-CFCHS T-joints is significant under axial tension and out-of-plane bending moment (see Figure 17 and 28).

- Parameter $\beta$ has little effect on the SCF in both CHS-to-CFCHS and empty T-joints under in-plane bending (see Figure 28). 
- The maximum SCF under out-of-plane bending in CHS-to-CFCHS T-joints is located at the chord saddle - tension side.

\section{ACKNOWLEDGEMENTS}

The authors wish to thank Western Sydney University (WSU) for providing Candidature Support Funds for this project. The authors are also grateful for the support given by the WSU Structures Laboratory staff, Mr Robert Marshall and Mr Murray Bolden.

\section{REFERENCES}

[1] B.-C. Chen, T.-L. Wang, Overview of concrete filled steel tube arch bridges in China, Practice periodical on structural design and construction 14(2) (2009) 70-80.

[2] B. Jardine, Fatigue life enhancement of tubular joints by grout injection, Offshore Technology Report-Health and Safety Executive OTH (1993).

[3] L. Tong, K. Wang, W. Shi, Y. Chen, Experimental study on stress concentration factors of concrete-filled circular hollow section T-joints under axial loading, Proceedings of 8 th pacific structural conference. Wairakei, New Zealand, 2007.

[4] L. Tong, K. Wang, W. Shi, Y. Chen, Experimental investigation on stress concentration factors of CHS-to-CFCHS T-joints subjected to in-plane bending, Proceedings of the 5th International Conference on Advances in Steel Structures, 2007, pp. 1003-1007.

[5] J. Chen, J. Chen, W.-1. Jin, Experimental investigation of stress concentration factor of concrete-filled tubular T joints, Journal of Constructional Steel Research 66(12) (2010) 15101515 .

[6] K. Wang, L.-W. Tong, J. Zhu, X.-L. Zhao, F.R. Mashiri, Fatigue behavior of welded Tjoints with a CHS brace and CFCHS chord under axial loading in the brace, Journal of Bridge Engineering 18(2) (2013) 142-152.

[7] F. Xu, J. Chen, W.-1. Jin, Experimental investigation of SCF distribution for thin-walled concrete-filled CHS joints under axial tension loading, Thin-Walled Structures 93 (2015) 149-157.

[8] X.L. Zhao, S. Herion, J.A. Packer, R.S. Puthli, G. Sedlacek, J. Wardenier, K. Weynand, A.M.van Wingerde, N.F. Yeomans, Design Guide for Circular and Rectangular Hollow Section Welded Joints under Fatigue Loading, CIDECT and TÜV-Verlag, CologneGermany, 2001.

[9] DNV.GL, Fatigue design of offshore steel structures, No. DNV.GL-RP-C203, 2016. [10] P. Smedley, P. Fisher, A review of stress concentration factors for tubular complex joints, Integrity of Offshore Structures, 1990, p. 279.

[11] P. Smedley, P. Fisher, Stress concentration factors for simple tubular joints, The First International Offshore and Polar Engineering Conference, International Society of Offshore and Polar Engineers, 1991.

[12] I.A. Musa, F.R. Mashiri, X. Zhu, Parametric study and equation of the maximum SCF for concrete filled steel tubular T-joints under axial tension, Thin-Walled Structures 129 (2018) 145-156. 
[13] AS1391, Metallic materials - Tensile testing at ambient temperature, Sydney, Australia, 2007.

[14] AWS-D1.1/D1.1M, Structural Welding Code - Steel, American Welding Society, 2015. [15] J. Wardenier, Y. Kurobane, J. Packer, D. Dutta, N. Yeomans, Design guide for circular hollow section (CHS) joints under predominantly static loading (1). CIDECT (Ed.) and Verlag TÜV Rheinland, Cologne, Germany, ISBN 3-88585-975-0, 2008.

[16] I. Musa, F. Mashiri, X. Zhu, Parametric study on concrete-filled steel tubular T-joints under axial load, Life-Cycle of Engineering Systems: Emphasis on Sustainable Civil Infrastructure, CRC Press, Delft The Netherlands, 2016, p. 418.

[17] ISO19902:2007, International Standard: Petroleum and natural gas industries — Fixed steel offshore structures, Switzerland, 2007.

[18] American Petroleum Institute, Recommended Practice 2A -WSD: 22nd edition, Planning, Designing, and Constructing Fixed Offshore Platforms-Working Stress Design, API Publishing Services, Washington, USA, 2014.

[19] M. Efthymiou, Development of SCF formulae and generalised influence functions for use in fatigue analysis, Offshore Tubular Joints, Surrey UK, 1988.

[20] I.A. Musa, F.R. Mashiri, Parametric Study and Equations of the Maximum SCF for Concrete Filled Steel Tubular T-Joints under in-plane and out-of-plane Bending, Steel and Composite Structures (under review) (2018).

[21] I.A. Musa, F.R. Mashiri, X. Zhu, Investigation on stress concentration factor in concretefilled steel tubular T-joints under out-of-plane bending moment, The 16th International Symposium on Tubular Structures, CRC Press, Melbourne, Australia, 2017. 
Table 2. Dimensions and geometric parameters

\begin{tabular}{cccccccc}
\hline \multirow{2}{*}{ Specimen } & Chord & \multicolumn{3}{c}{ Brace } & \multicolumn{2}{c}{ Parameter } \\
\cline { 2 - 8 } & $\begin{array}{l}\text { Diameter } \\
\mathrm{D}(\mathrm{mm})\end{array}$ & $\begin{array}{l}\text { Thickness } \\
\mathrm{T}(\mathrm{mm})\end{array}$ & $\begin{array}{l}\text { Diameter } \\
\mathrm{d}(\mathrm{mm})\end{array}$ & $\begin{array}{l}\text { Thickness } \\
\mathrm{t}(\mathrm{mm})\end{array}$ & $\beta$ & $\tau$ & $\gamma$ \\
\hline $\mathrm{T}-1$ & 165.10 & 5.32 & 48.30 & 5.27 & 0.29 & 0.99 & 15.50 \\
$\mathrm{~T}-2$ & 165.10 & 5.33 & 60.30 & 5.20 & 0.37 & 0.98 & 15.49 \\
$\mathrm{~T}-3$ & 165.10 & 5.33 & 114.30 & 5.23 & 0.69 & 0.98 & 15.49 \\
\hline
\end{tabular}

Table 3. Mechanical properties of the steel

\begin{tabular}{clllll}
\hline \multirow{2}{*}{ Specimen } & Part & $E_{s}(\mathrm{GPa})$ & $f_{y}(\mathrm{MPa})$ & $f_{u}(\mathrm{MPa})$ & $\varepsilon_{f}(\%)$ \\
\hline \multirow{2}{*}{$\mathrm{T}-1$} & Chord & 224 & 300 & 370 & 47.00 \\
& Brace & 227 & 373 & 399 & 23.30 \\
\hline \multirow{2}{*}{$\mathrm{T}-2$} & Chord & 204 & 290 & 370 & 41.42 \\
& Brace & 218 & 358 & 388 & 32.62 \\
\hline \multirow{2}{*}{$\mathrm{T}-3$} & Chord & 204 & 290 & 370 & 41.42 \\
& Brace & 180 & 300 & 365 & 35.93 \\
\hline
\end{tabular}

Table 4. Extrapolation region recommended by CIDECT [8]

\begin{tabular}{ccc}
\hline \multicolumn{2}{c}{ Chord Side } & Brace Side \\
\hline Crown location & Saddle location & Crown and Saddle location \\
\hline$l_{r, \text { min }}^{*}=0.4 \mathrm{~T}$ & $l_{r, \text { min }}^{*}=0.4 \mathrm{~T}$ & $l_{r, \text { min }}^{*}=0.4 t$ \\
$l_{r, \text { max }}^{* *}=0.4 \sqrt[4]{r t R T}$ & $l_{r, \text { max }}^{* *}=0.09 R$ & $l_{r, \text { max }}^{* *}=0.65 \sqrt{r t}$ \\
\hline$*$ Minimum & $* *)$ Minimum value for $l_{r, \text { is }} l_{r, m}+0.6 t$
\end{tabular}

*) Minimum value for $l_{r, \min }$ is $4 \mathrm{~mm}$. **) Minimum value for $l_{r, \max }$ is $l_{r, \min }+0.6 t$

Table 5. Experimental SCFs of the CHS-to-CFCHS T-joints under axial tension and compression

\begin{tabular}{|c|c|c|c|c|c|c|c|c|c|c|c|c|}
\hline \multirow{2}{*}{ Specimen } & \multicolumn{4}{|c|}{ Axial tension } & \multicolumn{4}{|c|}{ Axial compression } & \multicolumn{4}{|c|}{ Compression/tension } \\
\hline & Cs & $\mathrm{Cc}$ & Bs & $\mathrm{Bc}$ & Cs & $\mathrm{Cc}$ & Bs & $\mathrm{Bc}$ & Cs & $\mathrm{Cc}$ & Bs & $\mathrm{Bc}$ \\
\hline $\mathrm{T}-1$ & 6.00 & 5.34 & 3.10 & 0.57 & 2.00 & 3.44 & 1.31 & 1.37 & 0.33 & 0.64 & 0.42 & 2.40 \\
\hline $\mathrm{T}-2$ & 5.50 & 5.25 & 2.46 & 1.28 & 2.01 & 3.70 & 0.90 & 1.94 & 0.37 & 0.70 & 0.37 & 1.52 \\
\hline $\mathrm{T}-3$ & 3.88 & 7.87 & 2.44 & 2.41 & 3.09 & 5.56 & 1.00 & 3.29 & 0.80 & 0.71 & 0.41 & 1.37 \\
\hline
\end{tabular}

Table 6. Comparison of SCFs of the CHS-to-CFCHS T-joints test results under axial tension and design prediction for empty T-joints according to CIDECT [8] and DNV.GL[9].

\begin{tabular}{|c|c|c|c|c|c|c|c|c|c|c|c|c|}
\hline \multirow{2}{*}{ Specimen } & \multicolumn{4}{|c|}{ Test Results } & \multicolumn{4}{|c|}{$\begin{array}{c}\text { Predicted by CIDECT and } \\
\text { DNV.GL }\end{array}$} & \multicolumn{4}{|c|}{ Comparison Test/Predicted } \\
\hline & Cs & $\mathrm{Cc}$ & Bs & $\mathrm{Bc}$ & Cs & $\mathrm{Cc}$ & Bs & $\mathrm{Bc}$ & Cs & $\mathrm{Cc}$ & Bs & $\mathrm{Bc}$ \\
\hline $\mathrm{T}-1$ & 6.00 & 5.34 & 3.10 & 0.57 & 14.59 & 7.21 & 9.52 & 3.45 & 0.41 & 0.74 & 0.33 & 0.17 \\
\hline $\mathrm{T}-2$ & 5.50 & 5.25 & 2.46 & 1.28 & 15.73 & 7.12 & 10.10 & 3.36 & 0.35 & 0.74 & 0.24 & 0.38 \\
\hline T-3 & 3.88 & 7.87 & 2.44 & 2.41 & 15.51 & 8.17 & 9.67 & 3.60 & 0.25 & 0.96 & 0.25 & 0.67 \\
\hline
\end{tabular}


Table 7. Comparison of SCFs of the CHS-to-CFCHS T-joints test results under axial tension and design prediction for empty T-joints according to LR design guides [10, 11]

\begin{tabular}{|c|c|c|c|c|c|c|c|c|c|c|c|c|}
\hline \multirow{2}{*}{ Specimen } & \multicolumn{4}{|c|}{ Test Results } & \multicolumn{4}{|c|}{ Predicted by LR design guides } & \multicolumn{4}{|c|}{ Comparison Test/Predicted } \\
\hline & Cs & $\mathrm{Cc}$ & Bs & $\mathrm{Bc}$ & Cs & $\mathrm{Cc}$ & Bs & $\mathrm{Bc}$ & $\mathrm{Cs}$ & $\mathrm{Cc}$ & Bs & $\mathrm{Bc}$ \\
\hline T-1 & 6.00 & 5.34 & 3.10 & 0.57 & 11.87 & 7.82 & 6.67 & 1.78 & 0.51 & 0.68 & 0.46 & 0.32 \\
\hline $\mathrm{T}-2$ & 5.50 & 5.25 & 2.46 & 1.28 & 13.33 & 8.19 & 7.42 & 1.86 & 0.41 & 0.64 & 0.33 & 0.69 \\
\hline $\mathrm{T}-3$ & 3.88 & 7.87 & 2.44 & 2.41 & 13.42 & 9.72 & 7.66 & 1.81 & 0.29 & 0.81 & 0.32 & 1.33 \\
\hline
\end{tabular}

Table 8. Comparison of SCFs of the CHS-to-CFCHS T-joints test results under axial tension and the design prediction for CHS-to-CFCHS T-joints according to DNV.GL[9].

\begin{tabular}{|c|c|c|c|c|c|c|c|c|c|c|c|c|}
\hline \multirow{2}{*}{ Specimen } & \multicolumn{4}{|c|}{ Test Results } & \multicolumn{4}{|c|}{ Predicted DNV.GL } & \multicolumn{4}{|c|}{ Comparison Test/Predicted } \\
\hline & Cs & $\mathrm{Cc}$ & Bs & $\mathrm{Bc}$ & Cs & $\mathrm{Cc}$ & Bs & $\mathrm{Bc}$ & $\mathrm{Cs}$ & $\mathrm{Cc}$ & Bs & $\mathrm{Bc}$ \\
\hline $\mathrm{T}-1$ & 6.00 & 5.34 & 3.10 & 0.57 & 7.27 & 7.21 & 5.39 & 3.45 & 0.83 & 0.74 & 0.58 & 0.17 \\
\hline $\mathrm{T}-2$ & 5.50 & 5.25 & 2.46 & 1.28 & 7.84 & 7.12 & 5.68 & 3.36 & 0.70 & 0.74 & 0.43 & 0.38 \\
\hline $\mathrm{T}-3$ & 3.88 & 7.87 & 2.44 & 2.41 & 7.73 & 8.17 & 5.47 & 3.60 & 0.50 & 0.96 & 0.45 & 0.67 \\
\hline
\end{tabular}

Table 9. Comparison of the maximum SCFs of the CHS-to-CFCHS T-joints test results under axial tension and the maximum SCF for CHS-to-CFCHS T-joints predicted by the parametric equation developed by Musa et al [12].

\begin{tabular}{lccc}
\hline Specimen & $S C F_{\text {Max.Test }}$ & $S C F_{\text {Max.Predict }}$ & Comparison Predicted/Test \\
& & & \\
\hline T-1 & 6.00 & 6.60 & 1.10 \\
T-2 & 5.50 & 6.41 & 1.17 \\
T-3 & 7.87 & 7.69 & 0.98 \\
\hline
\end{tabular}

$S C F_{\text {Max.Test }}=$ Maximum SCF from test results.

$S C F_{\text {Max.Predict }}=$ Maximum SCF predicted by the parametric equation for CHS-to-CFCHS T-joints under axial tension.

Table 10. Comparison of experimental SCFs of the CHS-to-CFCHS T-joints under in-plane bending moment and design prediction for empty T-joints according to CIDECT [8] and DNV.GL[9].

\begin{tabular}{lllllll}
\hline \multirow{2}{*}{ Specimen } & \multicolumn{2}{l}{$\begin{array}{l}\text { Test Results } \\
\text { (Tension side) }\end{array}$} & \multicolumn{2}{l}{$\begin{array}{l}\text { Predicted by } \\
\text { CIDECT and DNV.GL }\end{array}$} & \multicolumn{2}{l}{$\begin{array}{l}\text { Comparison } \\
\text { Test/Predicted }\end{array}$} \\
\cline { 2 - 7 } & Cc & Bc & Cc & Bc & Cc & Bc \\
\hline T-1 & 2.31 & 1.20 & 3.77 & 3.02 & 0.61 & 0.40 \\
$\mathrm{~T}-2$ & 2.14 & 1.06 & 4.08 & 3.16 & 0.52 & 0.34 \\
$\mathrm{~T}-3$ & 1.82 & 1.47 & 4.21 & 3.06 & 0.43 & 0.48 \\
\hline
\end{tabular}

Table 11. Comparison of SCFs of the CHS-to-CFCHS T-joints test results under in-plane bending moment and design prediction for empty $\mathrm{T}$-joints according to LR design guides $[10,11]$

\begin{tabular}{|c|c|c|c|c|c|c|}
\hline \multirow[t]{2}{*}{ Specimen } & \multicolumn{2}{|c|}{$\begin{array}{l}\text { Test Results } \\
\text { (Tension side) }\end{array}$} & \multicolumn{2}{|c|}{$\begin{array}{l}\text { Predicted by } \\
\text { LR design guides }\end{array}$} & \multicolumn{2}{|c|}{$\begin{array}{l}\text { Comparison } \\
\text { Test/Predicted }\end{array}$} \\
\hline & $\mathrm{Cc}$ & $\mathrm{Bc}$ & $\mathrm{Cc}$ & $\mathrm{Bc}$ & $\mathrm{Cc}$ & $\mathrm{Bc}$ \\
\hline $\mathrm{T}-1$ & 2.31 & 1.20 & 3.17 & 1.89 & 0.73 & 0.63 \\
\hline $\mathrm{T}-2$ & 2.14 & 1.06 & 3.44 & 2.03 & 0.62 & 0.52 \\
\hline $\mathrm{T}-3$ & 1.82 & 1.47 & 3.55 & 2.23 & 0.51 & 0.66 \\
\hline
\end{tabular}


Table 12. Comparison of SCFs of the CHS-to-CFCHS T-joints test results under out-of-plane bending moment and design prediction for empty T-joints according to CIDECT [8], DNV.GL[9] and LR design guides[10, 11].

\begin{tabular}{|c|c|c|c|c|c|c|c|c|c|c|}
\hline \multirow{3}{*}{ Specimen } & \multicolumn{2}{|c|}{$\begin{array}{l}\text { Test Results } \\
\text { (Tension side) }\end{array}$} & \multicolumn{2}{|c|}{$\begin{array}{l}\text { Predicted by } \\
\text { CIDECT and } \\
\text { DNV.GL }\end{array}$} & \multicolumn{2}{|c|}{$\begin{array}{l}\text { Predicted by } \\
\text { LR design } \\
\text { guides }\end{array}$} & \multicolumn{4}{|c|}{$\begin{array}{c}\text { Comparison } \\
\text { Test/Predicted }\end{array}$} \\
\hline & $\mathrm{Cs}$ & Bs & $\mathrm{Cs}$ & Bs & $\mathrm{Cs}$ & $\mathrm{Bc}$ & (1) & $(2)$ & (1) & (2) \\
\hline & (1) & (2) & (3) & (4) & (5) & (6) & $\overline{(3)}$ & $\overline{(4)}$ & $\overline{(5)}$ & $\overline{(6)}$ \\
\hline $\mathrm{T}-1$ & 3.89 & 1.47 & 7.46 & 5.58 & 6.22 & 3.74 & 0.52 & 0.26 & 0.63 & 0.39 \\
\hline $\mathrm{T}-2$ & 5.23 & 2.33 & 9.14 & 6.61 & 7.73 & 4.42 & 0.57 & 0.35 & 0.68 & 0.53 \\
\hline $\mathrm{T}-3$ & 6.20 & 2.41 & 14.20 & 8.56 & 13.03 & 6.74 & 0.44 & 0.28 & 0.48 & 0.36 \\
\hline
\end{tabular}




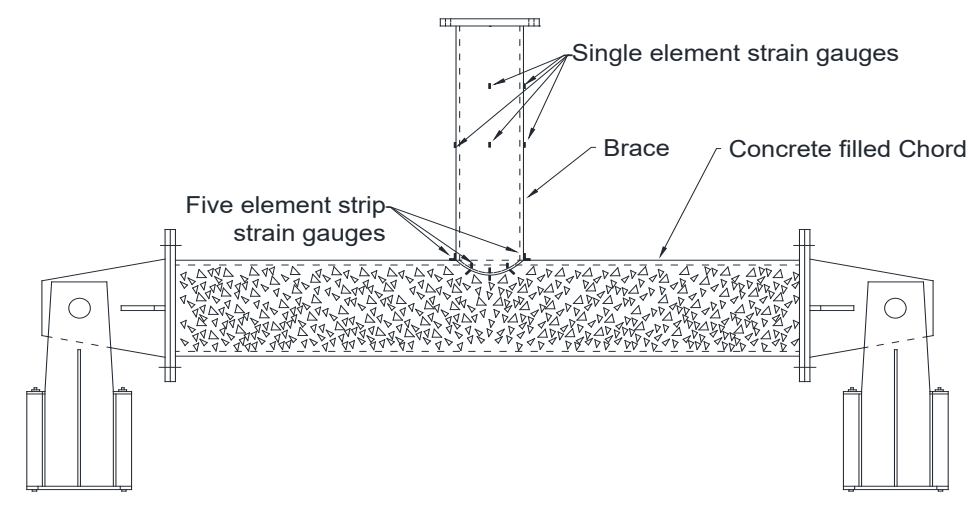

Figure 1. Boundary conditions

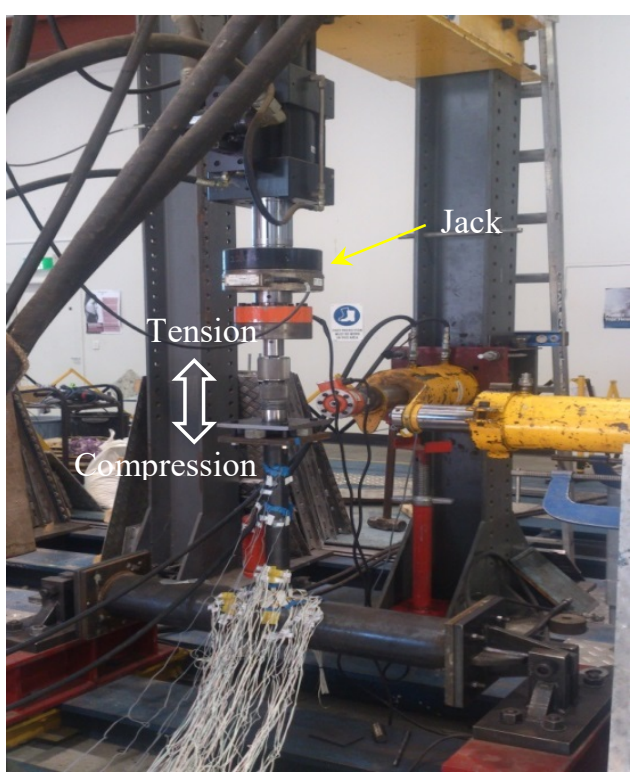

Figure 2. Specimen set up under axial tension and compression

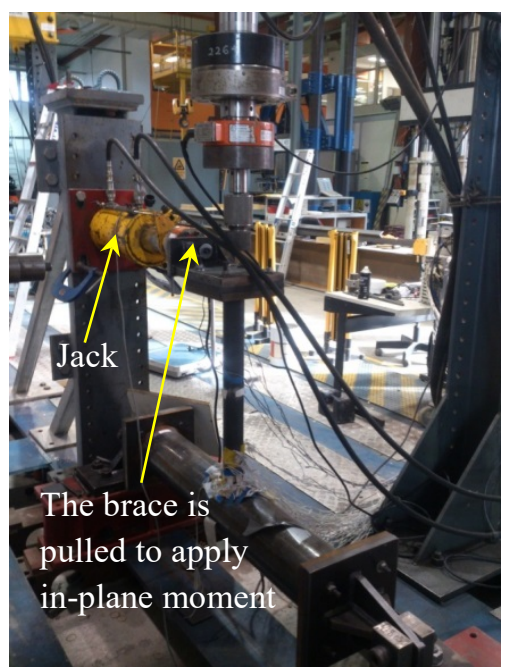

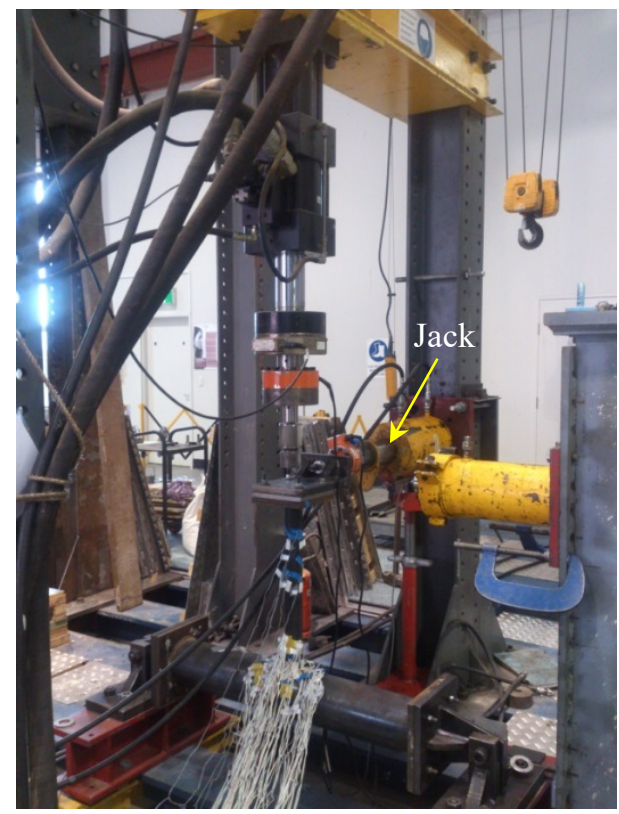

Figure 3. Specimen set up under out-of-plane bending moment

Figure 4. Specimen set up under in-plane bending moment 


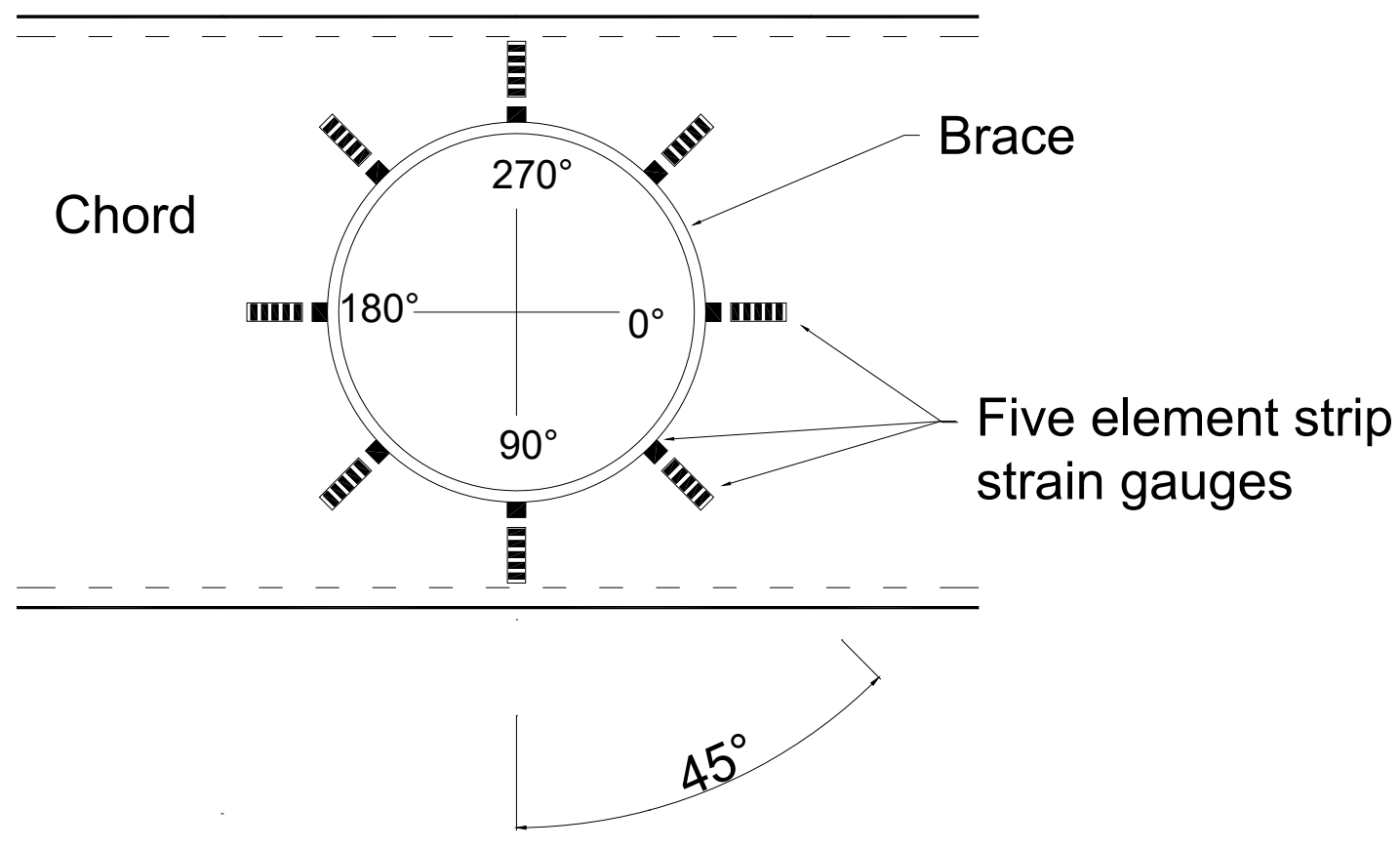

Figure 5. Strain gauge locations

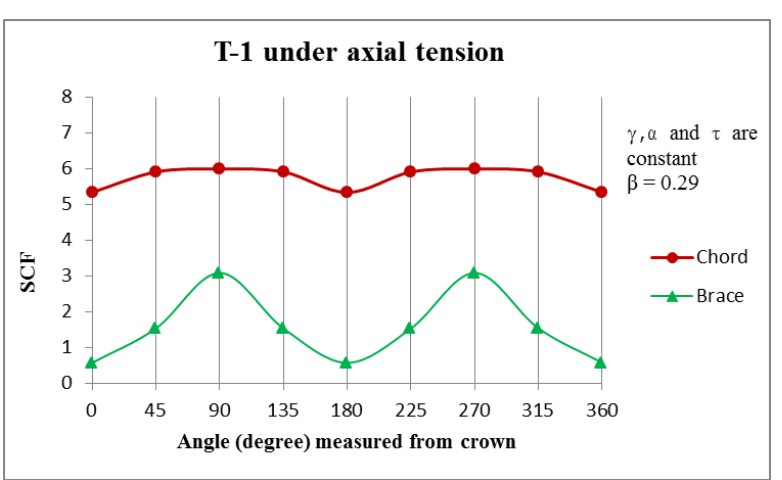

Figure 6. Distribution of SCF around Chord-Brace intersection in specimen $\mathrm{T}-1$ under axial tension

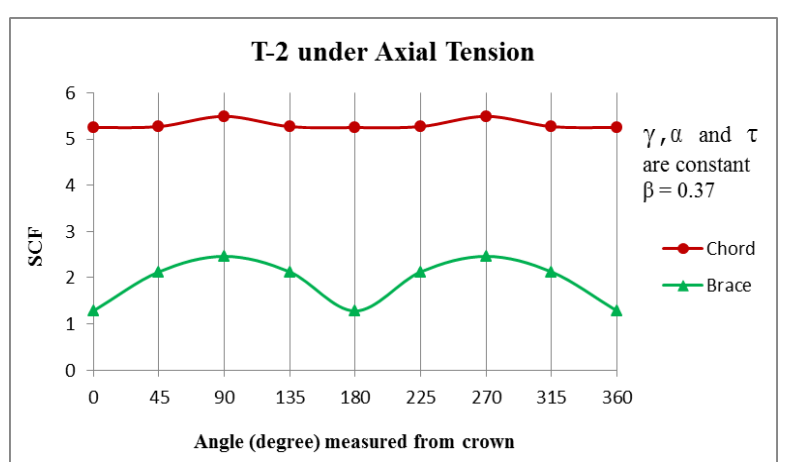

Figure 8. Distribution of SCF around Chord-Brace intersection in specimen $\mathrm{T}-2$ under axial tension

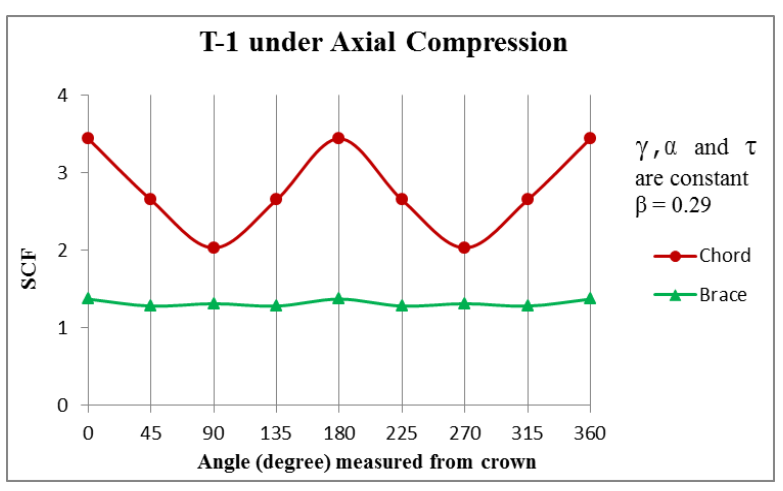

Figure 7. Distribution of SCF around Chord-Brace intersection in specimen $\mathrm{T}-1$ under axial compression

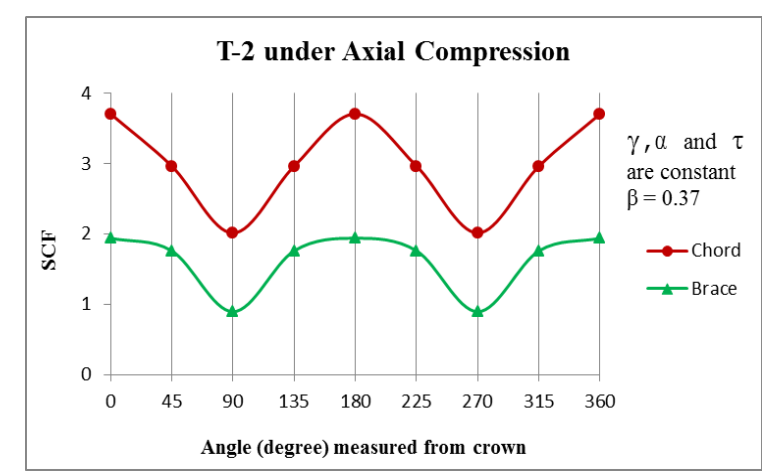

Figure 9. Distribution of SCF around Chord-Brace intersection in specimen $\mathrm{T}-2$ under axial compression 


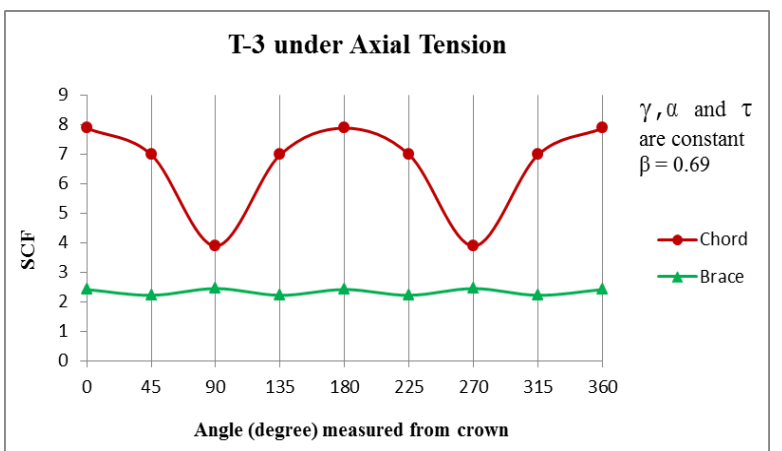

Figure 10. Distribution of SCF around Chord-Brace intersection in specimen $\mathrm{T}-3$ under axial tension

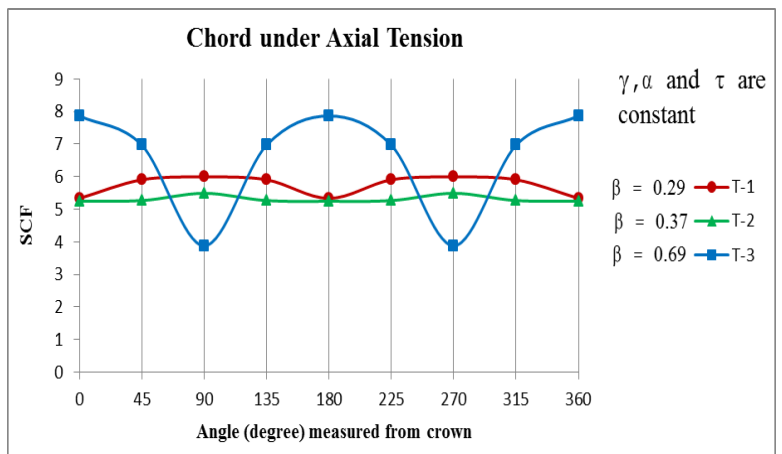

Figure 12. Distribution of SCF around the Chord in the three specimens under axial tension

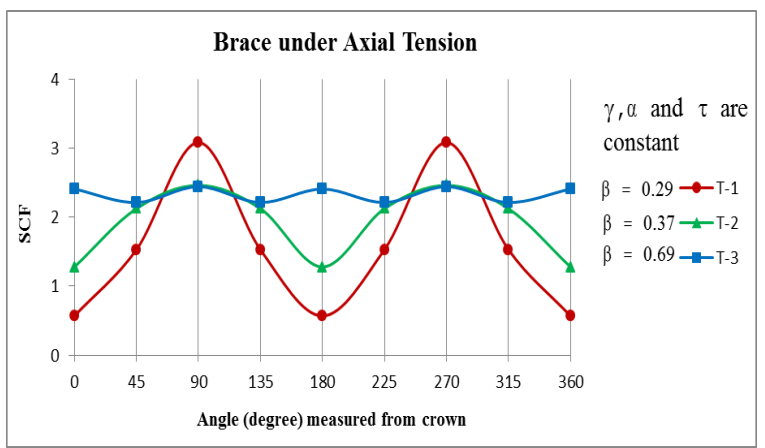

Figure 14. Distribution of SCF around the Brace in the three specimens under axial tension

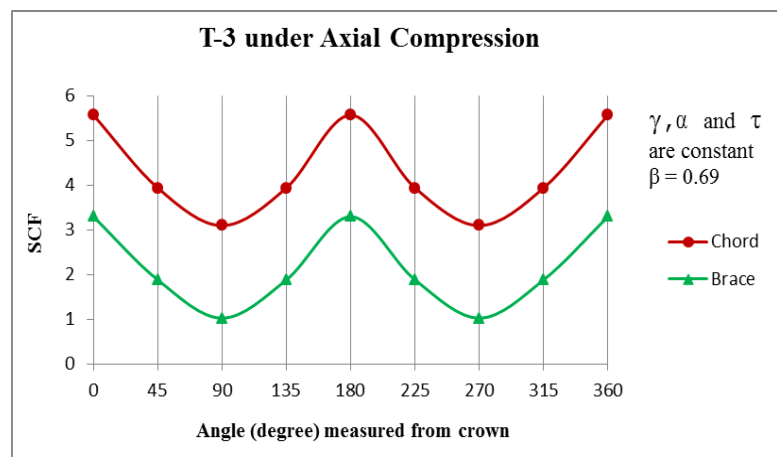

Figure 11. Distribution of SCF around Chord-Brace intersection in specimen T-3 under axial compression

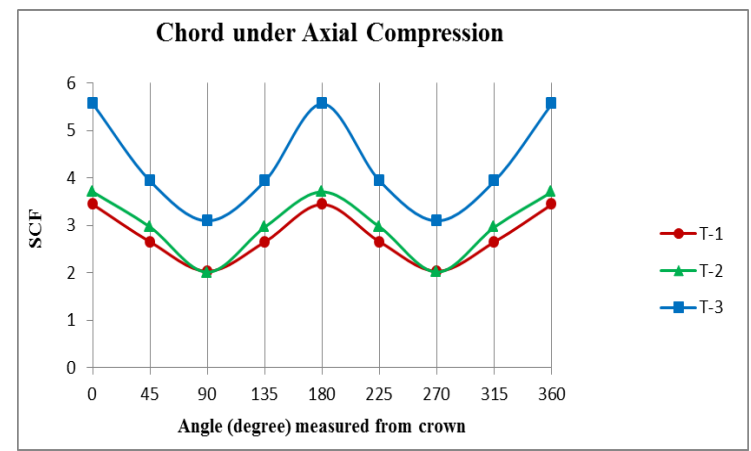

Figure 13. Distribution of SCF around the Chord in the three specimens under axial compression

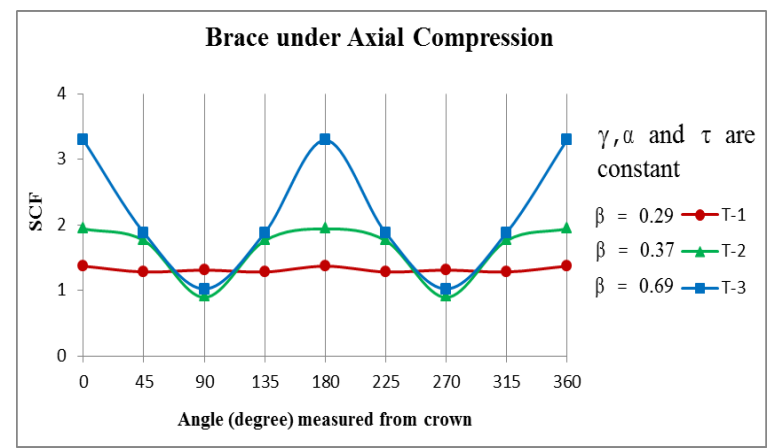

Figure 15. Distribution of SCF around the Brace in the three specimens under axial compression

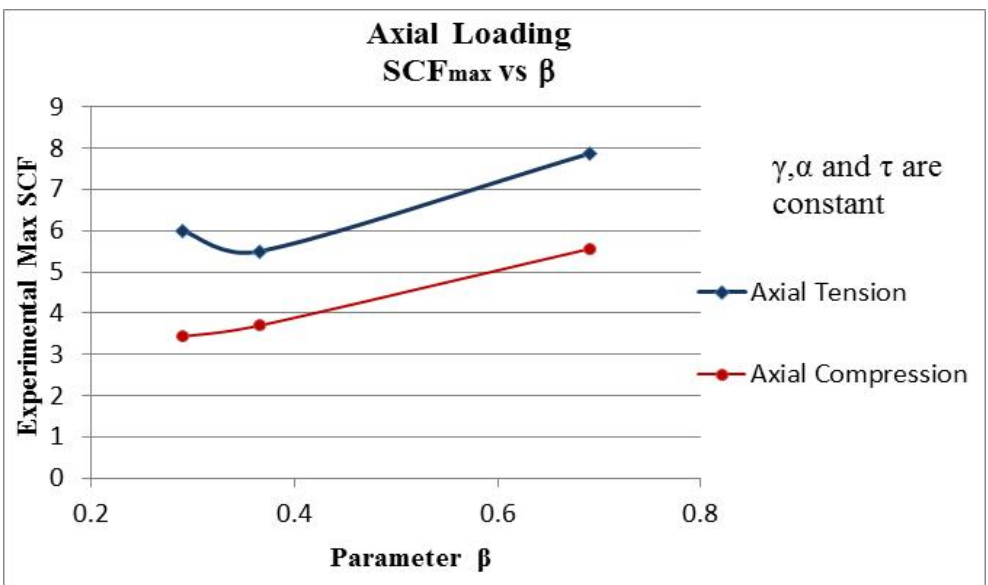

Figure 16. Variation of the Experimental $\mathrm{SCF}_{\max }$ under axial tension and compression with parameter $\beta$ 


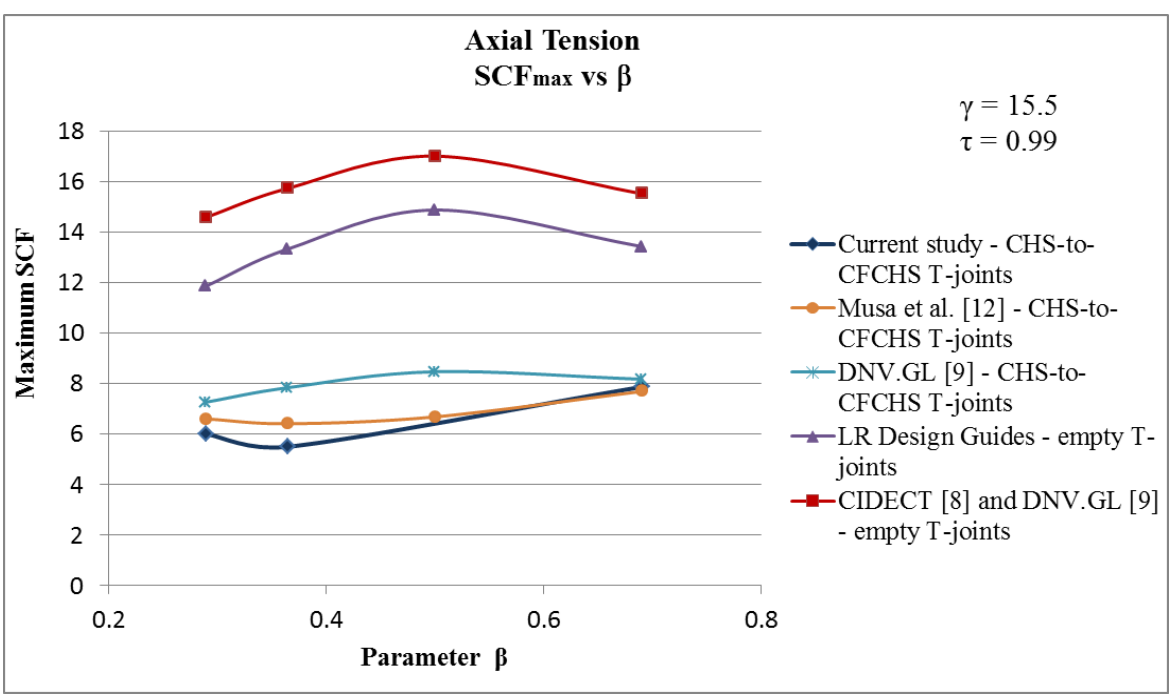

Figure 17. Variation of the maximum SCF under axial tension with parameter $\beta-$ CHS-to-CFCHS and empty T-joints.

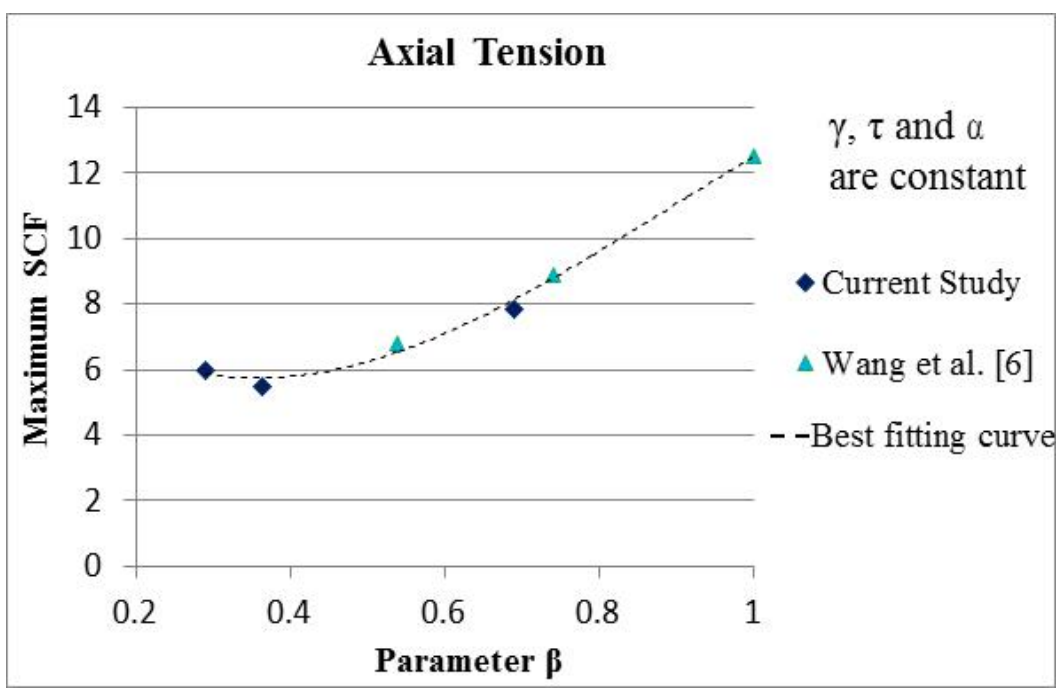

Figure 18. Variation of the maximum Experimental SCF under axial tension with parameter $\beta$

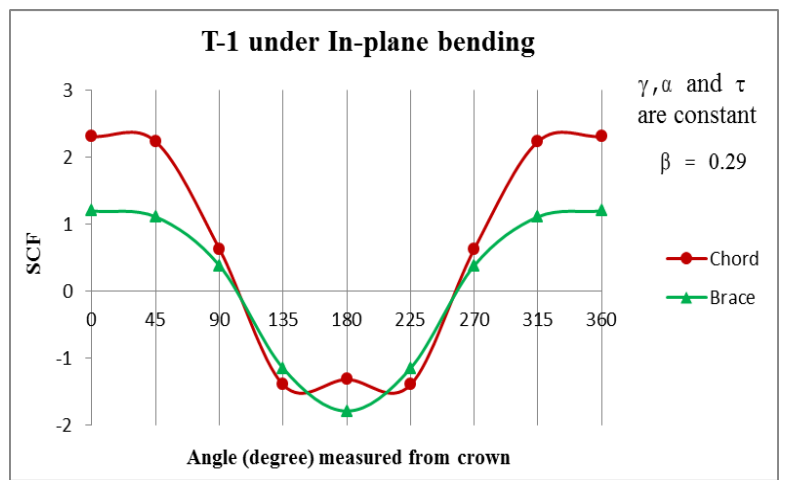

Figure 19. Distribution of SCF around Chord-Brace intersection in specimen $\mathrm{T}-1$ under in-plane bending

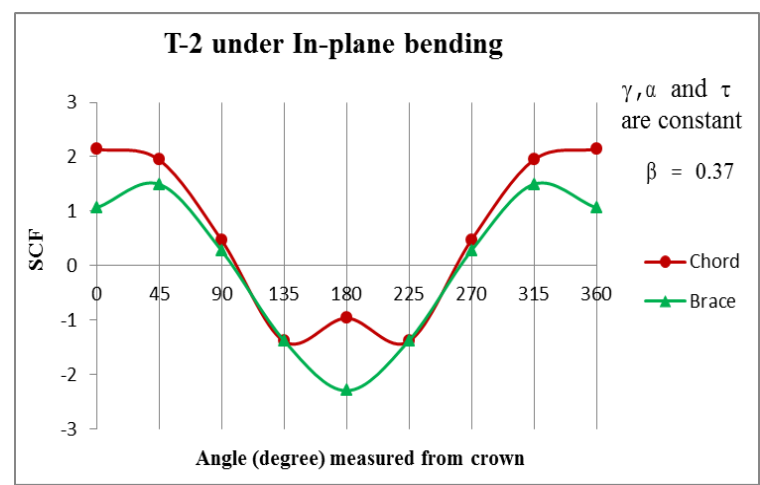

Figure 20. Distribution of SCF around Chord-Brace intersection in specimen T-2 under in-plane bending 


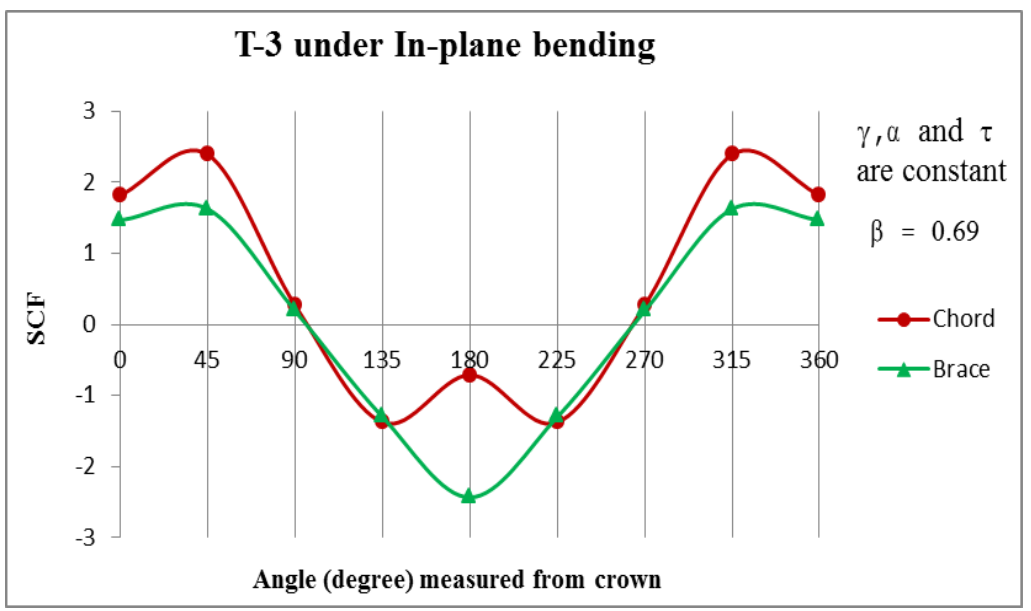

Figure 21. Distribution of SCF around Chord-Brace intersection in specimen T-3 under in-plane bending

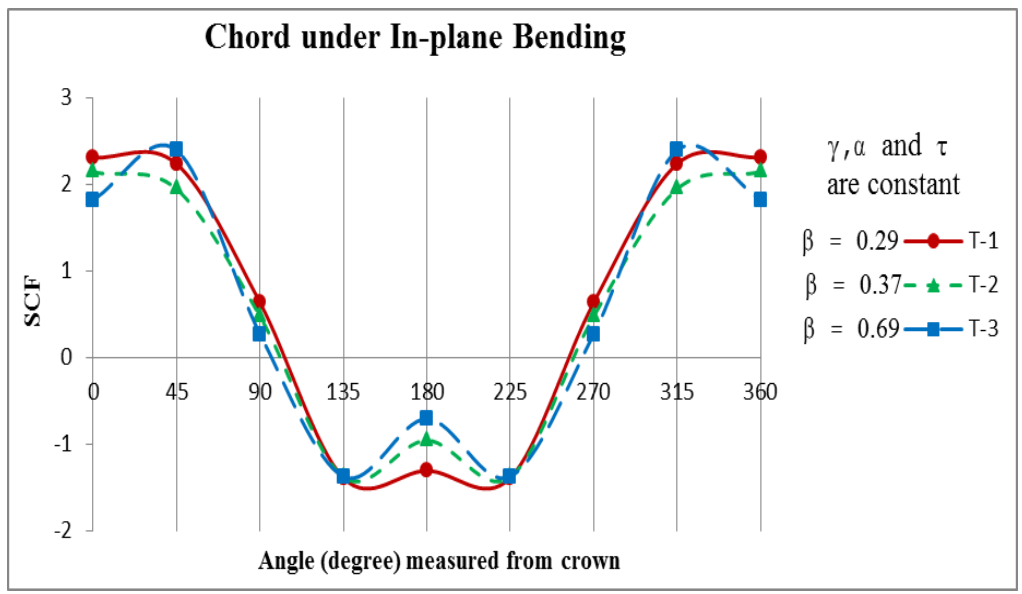

Figure 22. Distribution of SCF around the Chord in the three specimens under in-plane bending

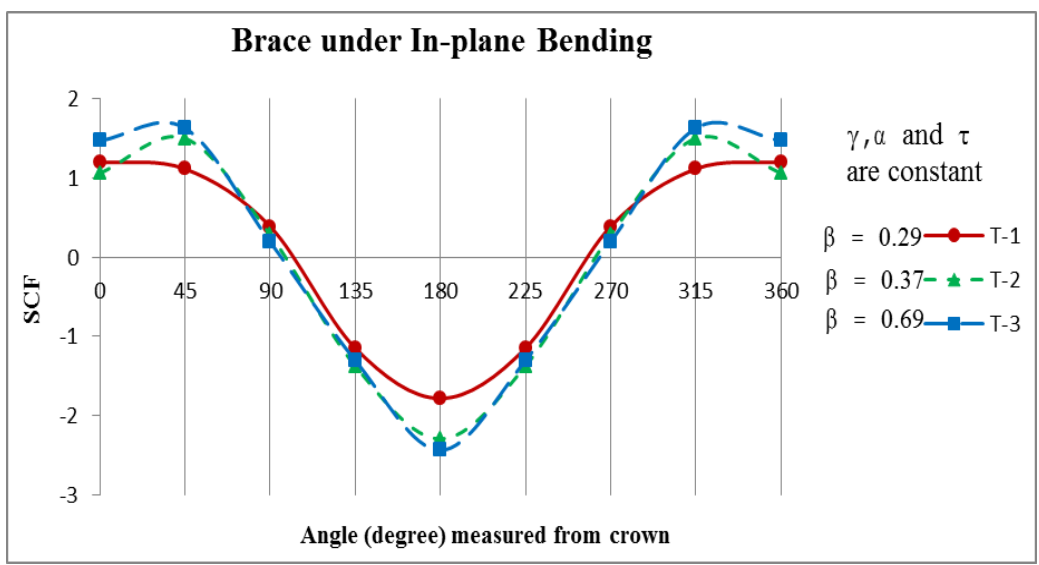

Figure 23. Distribution of SCF around the Brace in the three specimens under in-plane bending 


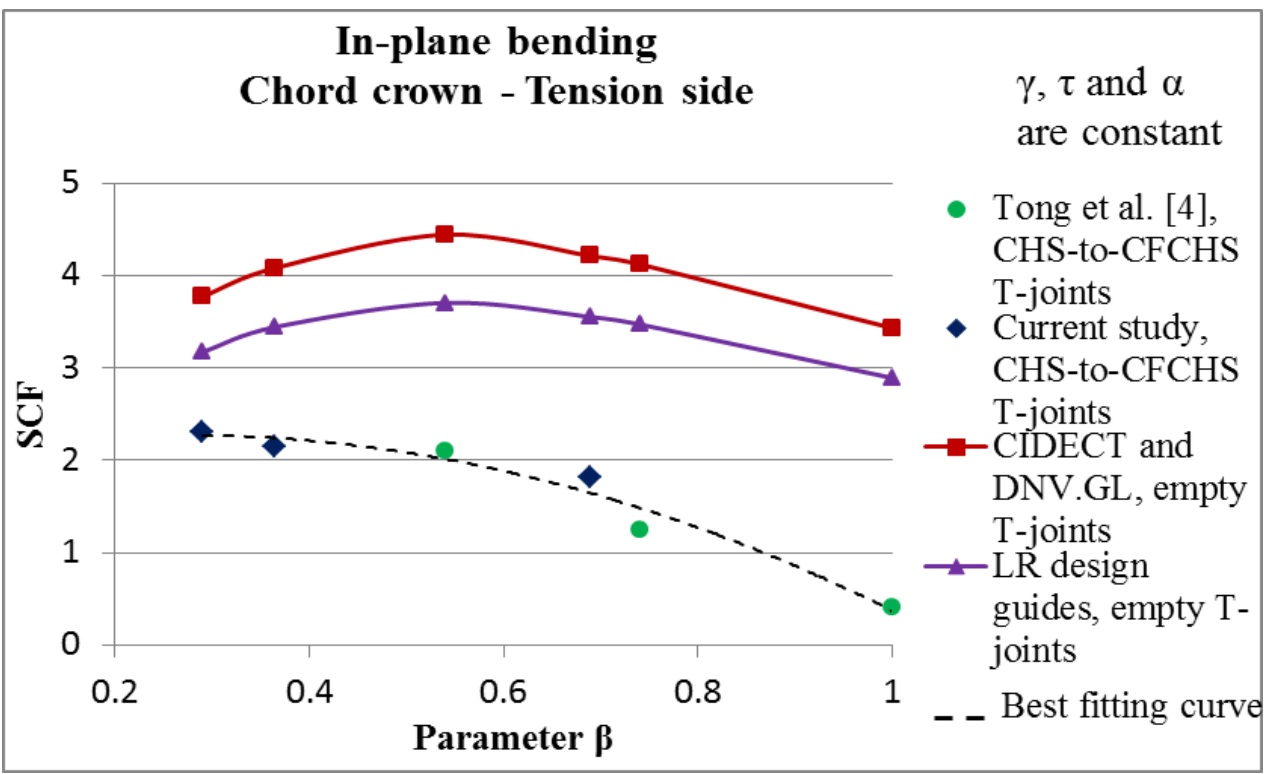

Figure 24. Variation of the SCF on the chord crown position on the side under tension subjected to in-plane bending moment with parameter $\beta$

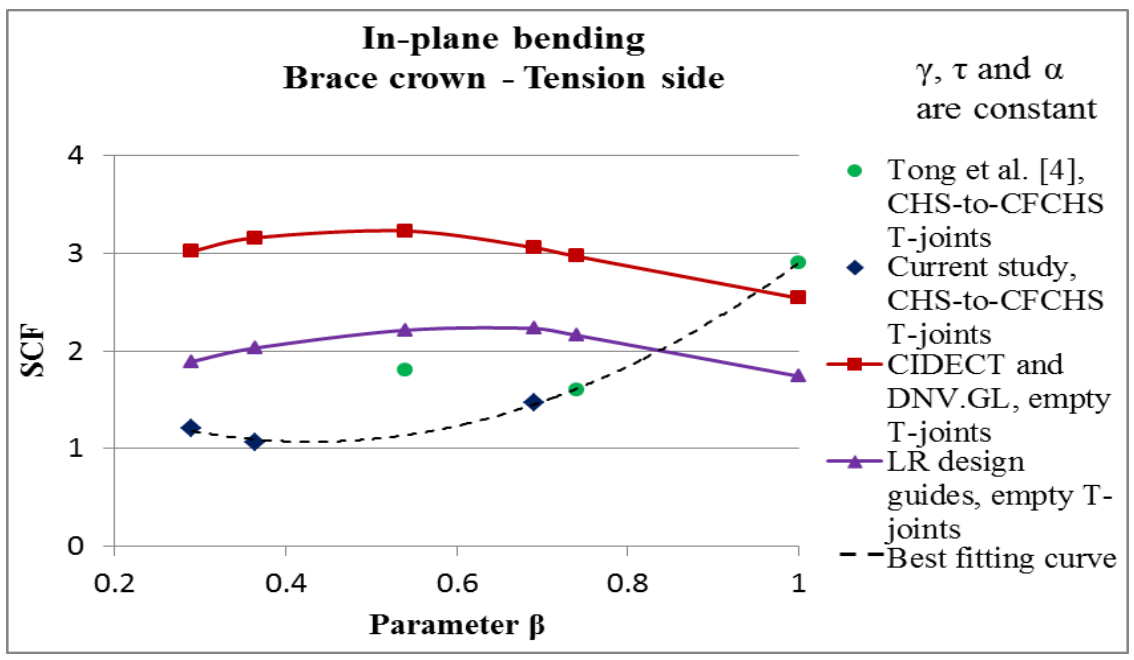

Figure 25. Variation of the SCF on the brace crown position on the side under tension subjected to in-plane bending moment with parameter $\beta$

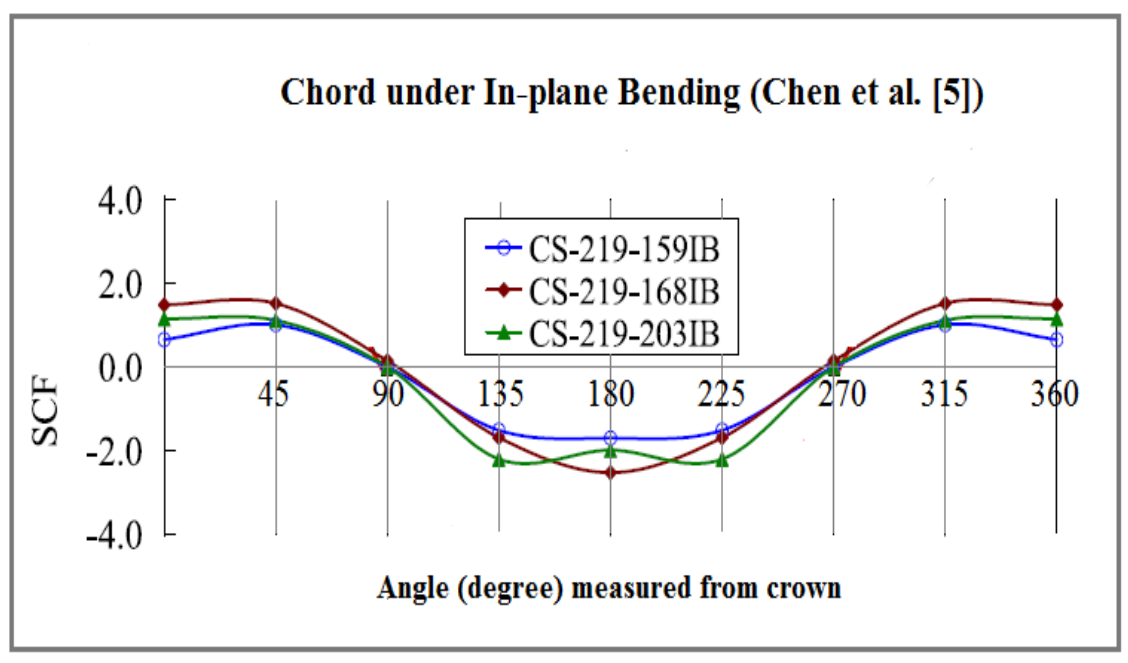

Figure 26. Distribution of SCF around the Chord in the three CHS-to-CFCHS specimens tested by Chen et al. [5] under in-plane bending 


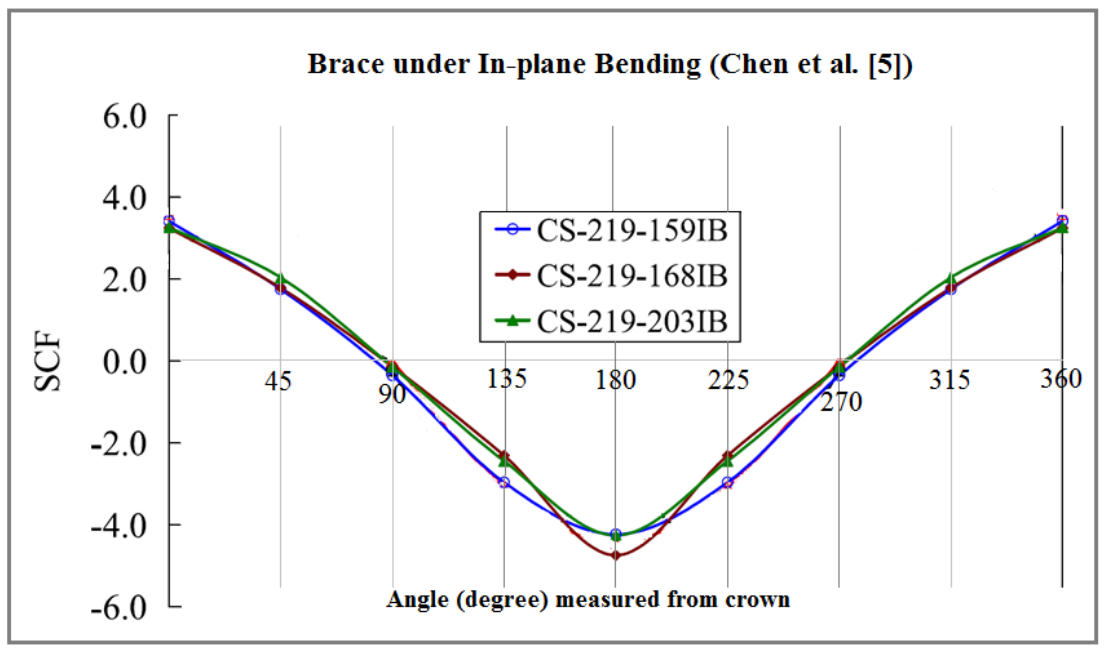

Figure 27. Distribution of SCF around the Brace in the three CHS-to-CFCHS specimens tested by Chen et al. [5] under in-plane bending

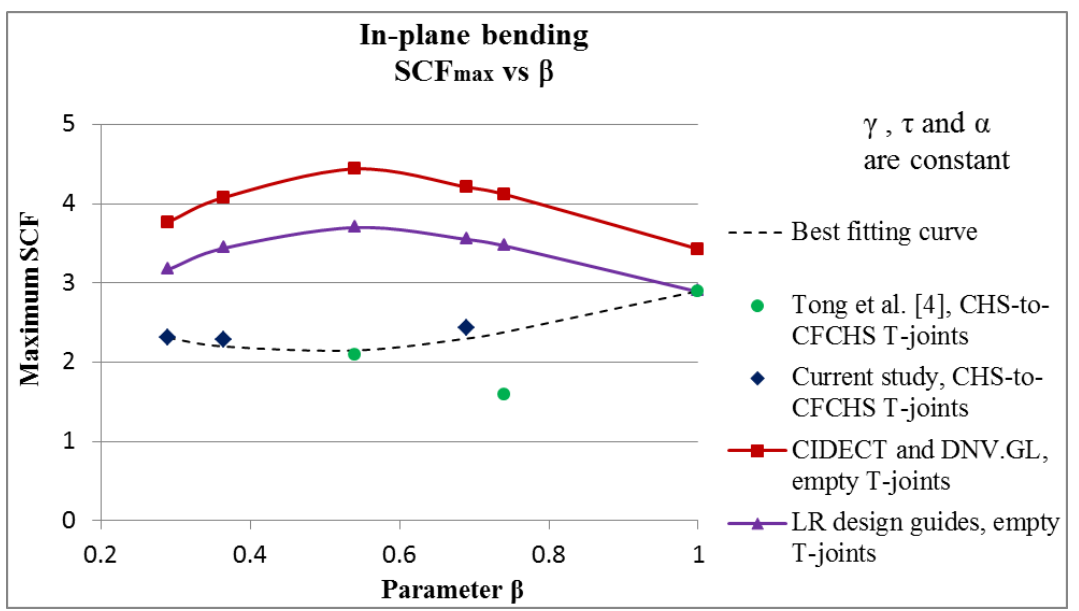

Figure 28. Variation of the maximum SCF under in-plane bending with parameter $\beta$ - CHS-to-CFCHS and empty T-joints.

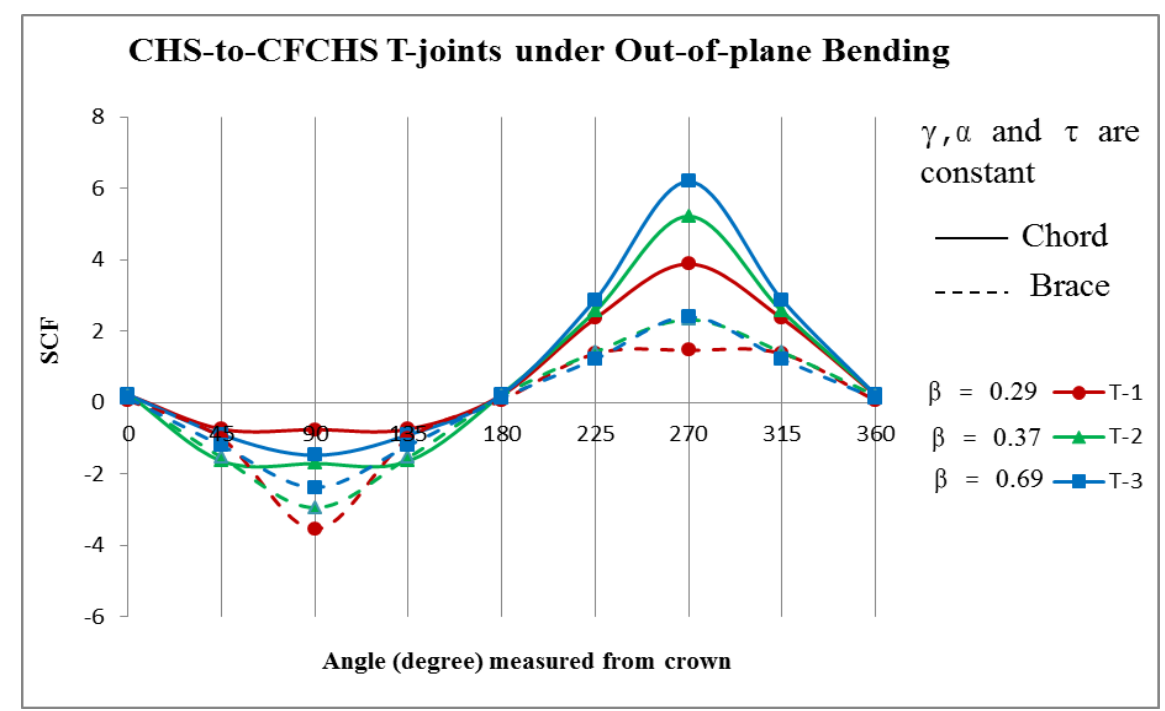

Figure 29. Distribution of the SCF around the Chord and brace of the three specimens under out-of-plane bending 


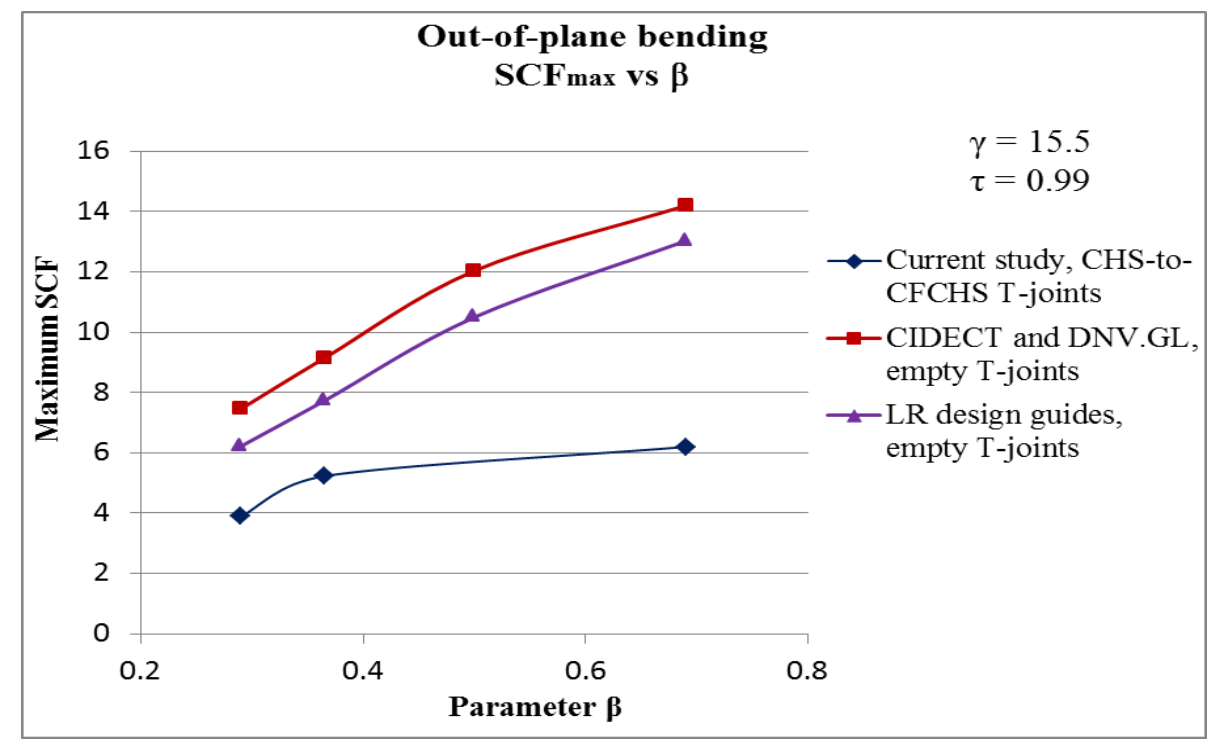

Figure 30. Variation of the maximum SCF under out-of-plane bending with parameter $\beta$ - CHS-to-CFCHS and empty T-joints. 